
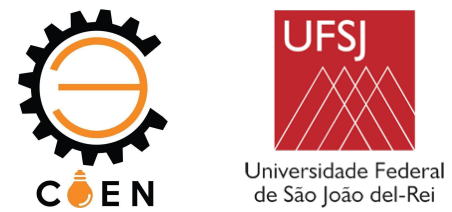

\title{
DESENVOLVIMENTO DE PROTÓTIPO DE SISTEMA DE ALARME PARA AMBIENTE LABORATORIAL
}

\author{
Paulo Raimundo Gomes de Lima ${ }^{(1)}$ (paulolima.5454@gmail.com), Marcos Vinícius Silvestre Carneiro ${ }^{(1)}$ \\ (m.viniciussilvestrec@gmail.com), Ana Paula Lima dos Santos ${ }^{(1)}$ (anapaula.lima@ifmg.edu.br), Gustavo \\ Lobato Campos ${ }^{(1)}$ (gustavo.lobato@ifmg.edu.br).
}

${ }^{(1)}$ IFMG - Campus Formiga - Engenharia Elétrica - Rua São Luiz Gonzaga, s/nº, São Luiz, Formiga, Minas Gerais

RESUMO: Ambientes laboratoriais possuem equipamentos de alto valor financeiro, fato que eleva a probabilidade de possiveis furtos nesses locais. Na maioria dos casos é empregada segurança armada, para que não aconteçam tais ocorrências. Neste contexto, a utilização de tecnologias de controle e automação residencial torna-se uma alternativa, especificamente sistemas de alarme sensorial, cuja finalidade é delimitar e controlar o fluxo de pessoas em ambientes definidos, de modo a reduzir a possibilidade de roubos. Portanto, este trabalho apresenta o desenvolvimento de um modelo em escala reduzida de um alarme para um ambiente laboratorial. Tal dispositivo utiliza a plataforma embarcada Arduino e inclui sensoriamento por presença e por contato, sistema de alarme sonoro e luminoso e controle de acesso realizado por senha predefinida, a qual é inserida por um teclado e visualizada em uma tela. $O$ protótipo possui a função de monitorar o ambiente de forma automatizada, de modo que uma vez trancado pelos responsáveis terá o seu acesso restrito.

PALAVRAS-CHAVE: Sistema de alarme, tecnologias de controle e automação, Arduino.

\section{INTRODUÇÃO}

A segurança atualmente tem sido um assunto bastante relevante no cotidiano, não apenas no que diz respeito à segurança pessoal, mas patrimonial também, o que aumenta o seu destaque. Como ressaltado por MARCHESAN (2012), estudos realizados em 2009 demonstraram que 47,2\% da população brasileira com 10 anos ou mais de idade se sente insegura na cidade em que mora e 21,4\% da população se sente insegura no domicílio em que reside.

No último ano o investimento em sistemas de segurança eletrônica residencial aumentou devido a sensação de insegurança dentro das residências, cerca de $69 \%$ dos prestadores de serviço efetuaram projetos para residências, tendo uma maior demanda por videomonitoramento e sistemas de alarme com e sem fio (HABICAMP, 2018).

Com base nesses dados percebe-se uma maior tendência na busca por segurança domiciliar, cujos métodos aplicados são variados, tais como: instalações de alarmes, câmeras, seguranças particulares e entre outros. No entanto, tais procedimentos podem ser financeiramente inviáveis, com um custo relativamente alto, o que torna difícil a aquisição destes por pessoas que possuem menores recursos financeiros.

Neste cenário, com um foco em ambientes educacionais, nos quais os laboratórios de ensino podem possuir a presença de computadores e outros equipamentos específicos de alto valor, a questão de segurança patrimonial se torna necessária. Tais ambientes usualmente possuem acesso restrito quando fora do horário de aula. Vale ressaltar ainda que, essas instituições normalmente 

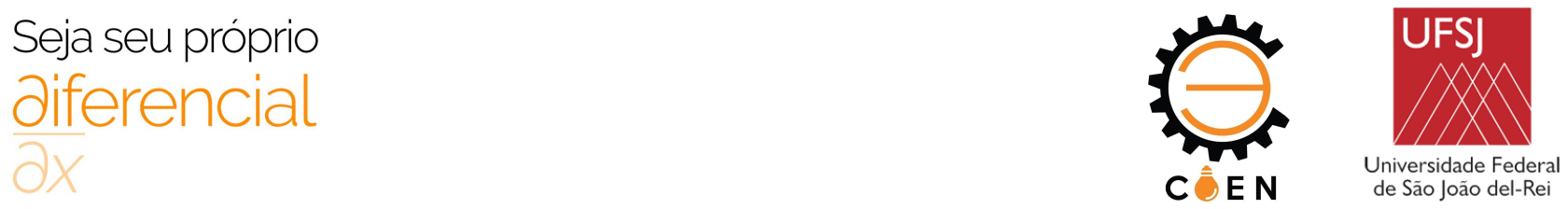

utilizam da segurança armada por empresas terceirizadas, o que muitas vezes se torna dispendioso do ponto de vista econômico. Sendo assim, se justifica a importância de sistemas de monitoramento automatizados para os mesmos. Portanto, diante de tal necessidade se justifica o desenvolvimento deste trabalho, com foco específico para ambiente laboratorial do IFMG Campus Formiga.

\section{OBJETIVO}

Desenvolver um protótipo de sistema de alarme para ambiente laboratorial, a fim de reduzir os valores gastos com segurança armada e consequentemente a probabilidade de roubo em tais ambientes, os quais possuem objetos de alta relevância.

\section{REFERENCIAL TEÓRICO}

\subsection{Sistemas de alarme}

Os sistemas de alarmes possuem a função de monitorar locais definidos e alertar os usuários e pessoas que estejam próximo ao local caso ocorra alguma irregularidade. Para o funcionamento desses equipamentos são necessários três blocos principais: entrada, controle e saída (BUCKMAN, 2016).

O bloco de entrada é composto por sensores e teclas (as quais compõem um teclado), os mesmos são responsáveis pela interação dos fatores externos com o bloco de controle. Os dados enviados por estes componentes normalmente são sinais analógicos ou digitais.

O controle é realizado por um circuito eletrônico, o qual é capaz de tratar os dados de entrada para a tomada de decisão. Essas informações são responsáveis para a liberação da entrada dos usuários ou para a ativação das saídas do sistema. As plataformas de prototipagem, como o microcontrolador Arduino, facilitam este tipo de implementação, por se tratar de um dispositivo com hardware e software open source (código aberto), o que possibilita a compatibilidade com uma infinidade de equipamentos.

O bloco de saída é responsável por emitir sinais de alerta. Na maioria dos sistemas são utilizados atuadores sonoros e luminosos, como sirenes e luzes. Na Figura 1 é possível visualizar o processo de comunicação do sistema.

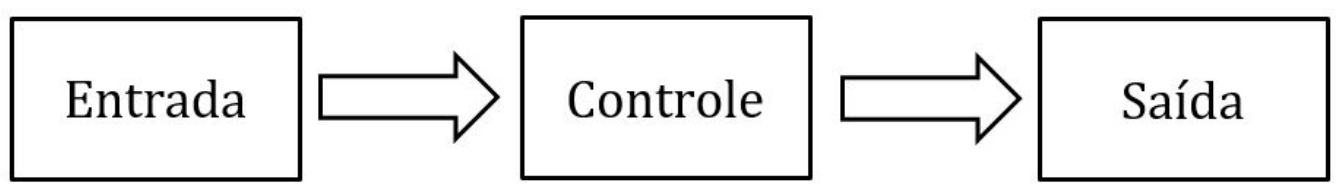

Figura 1. Blocos principais para o funcionamento de sistemas de alarme.

Fonte: Elaborado pelos autores.

\subsection{Sensores}

\subsubsection{Sensor de presença infravermelho}



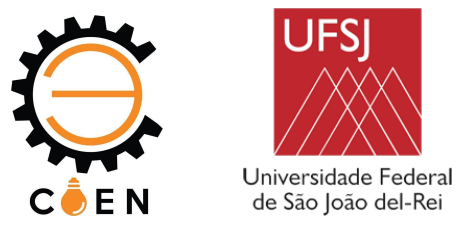

Os sensores de presença tem diversas aplicações devido as suas funcionalidades. Estes têm como principal função a detecção de movimento de determinado objeto por meio de radiação infravermelha.

Como explicado por NEVES (2015) os sensores passivos são ativados quando detectam alguma alteração da radiação infravermelha por meio de um receptor e tem como vantagem em relação aos sensores ativos uma maior área de captura. O sensor PIR ou também conhecido como sensor piroelétrico, atua como sensor passivo, cujo princípio de funcionamento ocorre conforme demonstrado na Figura 2.
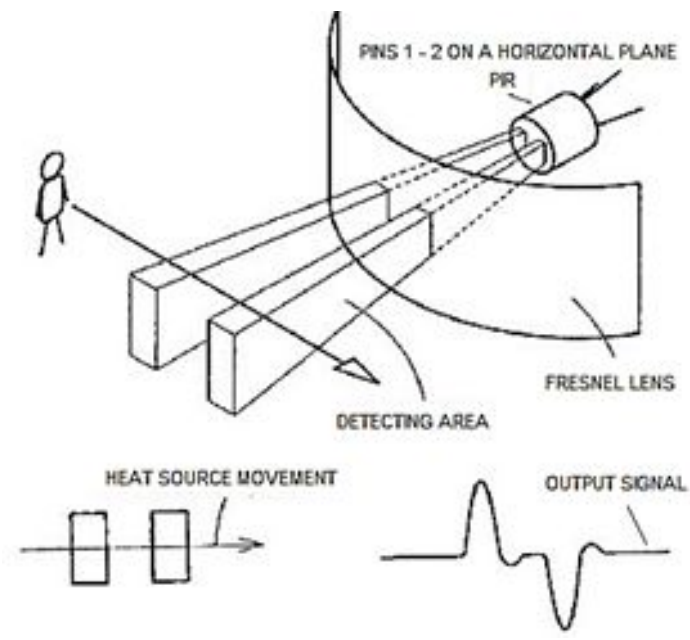

Figura 2. Princípio de funcionamento do Sensor PIR.

Fonte: (MADEIRA, 2017).

Para determinadas aplicações é viável a utilização do módulo eletrônico que já possui o sensor implementado. O módulo de sensor PIR HC-SR501 possui um ajuste de alcance de 3 a 7 metros de distância. Possui alimentação de 5V (volts) e tem como vantagem um ajuste no tempo de retardo e sensibilidade. Quando a variação infravermelha é detectada dentro da sua área de alcance é gerado um pulso de $3,3 \mathrm{~V}$ no seu pino de saída com um tempo de retardo máximo de 200ms (milisegundos) (NEVES, 2015). A Figura 3 demonstra o módulo HC-SR501.

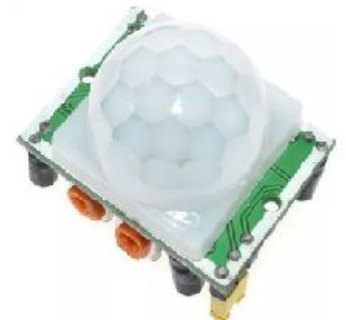

(a)

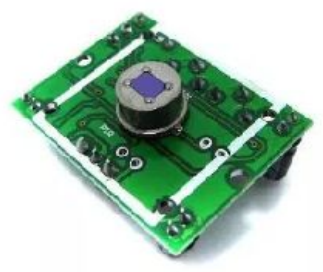

(b)

Figura 3. (a) módulo sensor PIR HC-SR501 com o invólucro (b) sensor PIR visível .

Fonte: (MADEIRA, 2017). 
O invólucro branco por cima do sensor proporciona uma maior área de alcance para o sensor PIR.

\subsubsection{Sensor magnético}

Os sensores magnéticos possuem a finalidade de detectar a modificação da distância entre dois pontos fixados, o que determinará a abertura ou fechamento de um contato.

Estes dispositivos são compostos por um bulbo de vidro e no seu interior existem lâminas metálicas separadas milimetricamente, as quais sofrem ação de campos magnéticos. Em condições normais as lâminas estão afastadas, assim o componente funciona como uma chave aberta e não há circulação de corrente no mesmo, ou seja, o circuito elétrico está aberto. O circuito elétrico é fechado quando se aproxima um ímã permanente do dispositivo. A ação do campo magnético faz com que as lâminas se magnetizem e se aproximem, proporcionando a circulação de corrente no circuito. Na Figura 4 é apresentado o funcionamento do sensor magnético conforme descrito (MARCHESAN, 2012).

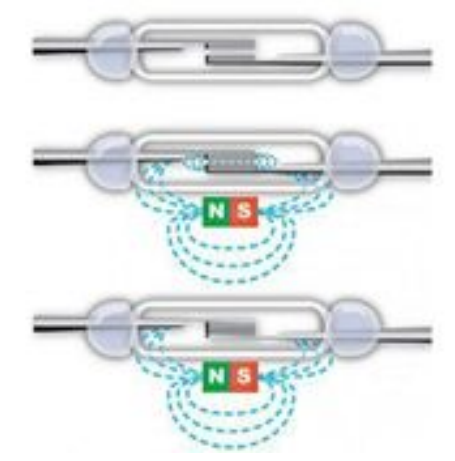

Figura 4. Funcionamento do sensor magnético.

Fonte: (MOTA, 2019).

Em aplicações como sistemas de alarmes os sensores magnéticos são utilizados em pontos estratégicos nas portas e janelas. Na Figura 5 é possível visualizar um sensor magnético do tipo aparente, indicado para uso em portas e janelas.

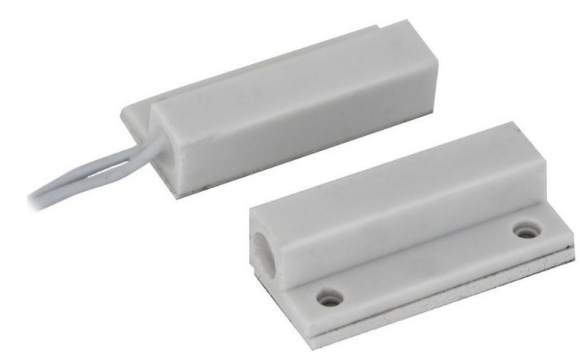

Figura 5. Sensor magnético do tipo aparente.

Fonte: (LIMA, 2017). 

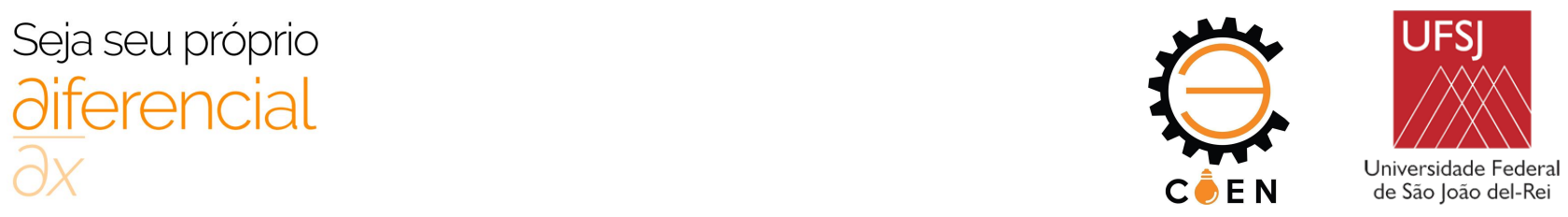

Em sensores deste modelo a caixa com as lâminas é presa em um ponto fixo e tem seus terminais conectados por fios à central de controle, já a caixa com o ímã é fixada na parte móvel do acesso. Quando a porta está fechada, por exemplo, o ímã está próximo das lâminas, assim o contato permanece fechado e envia sinal lógico alto como entrada. No momento em que a porta é aberta, o circuito se abre, enviando um sinal de nível lógico baixo para o sistema de controle (BRAGA, 2014).

\subsection{Controle}

\subsubsection{Microcontrolador Arduino}

O microcontrolador Arduino é amplamente utilizado em desenvolvimento de protótipos, visto que o mesmo possui baixo custo, é open source e possui uma comunidade que compartilha um leque de informações sobre a placa (ARDUINO, 2017).

Dentre os modelos de placas Arduino, a mais utilizada é a versão Uno, a qual pode ser observada na Figura 6, por possuir um número de portas que atende a diversas aplicações e compatibilidade com muitos shields disponíveis no mercado.

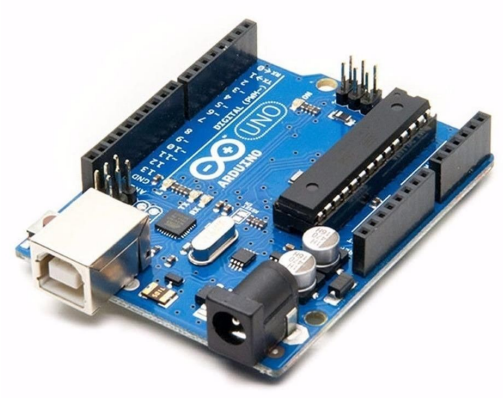

Figura 6. Arduino Uno.

Fonte: (ARDUINO, 2017).

O Arduino Uno possui como principal componente o microcontrolador Atmel Atmega328, um dispositivo de 8 bits da família AVR. A placa possui 14 pinos que podem ser utilizados como entradas e saídas digitais e 6 pinos de entrada analógica, que também possibilitam a função digital. Estes pinos operam com uma tensão de $5 \mathrm{~V}$ e uma corrente de até $40 \mathrm{~mA}$ (miliampères). Os pinos possuem resistores de pull-up interno que podem ser habilitados via software. A placa é programada através de comunicação serial, por meio de um ambiente de desenvolvimento integrado próprio. $\mathrm{O}$ microcontrolador vem programado com o bootloader, dessa forma não é necessário um programador para fazer a gravação do binário da placa (SOUZA, 2013).

\subsection{Atuadores}

\subsubsection{Buzzer}



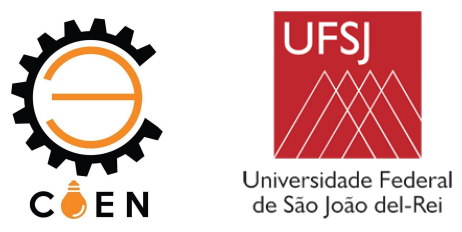

Um buzzer, do português sirene, é um dispositivo capaz de converter sinal elétrico em ondas sonoras. São utilizados para sinalização e reprodução de som, por permitir o controle da melodia através do sinal de entrada.

Estes dispositivos são constituídos de materiais piezoelétricos, como quartzo e alguns tipos de cerâmicas. Quando estes materiais são deformados, uma diferença de potencial elétrico é desenvolvida em suas extremidades e, inversamente, quando submetidos a uma certa tensão realizam o mesmo comportamento, como visualizado na Figura 7(a). Deste modo, é possível aproveitar de tal deformação para fazê-lo vibrar em uma determinada frequência (BRAGA, 2017).

Segundo BRAGA (2017) dispositivos utilizados em tensão contínua, que trabalham em tensões de operação de 3 a 15V, produzem sons em frequência de $2800 \mathrm{~Hz}$ (hertz). Na figura 7(b) é apresentado um buzzer que opera nestas condições.

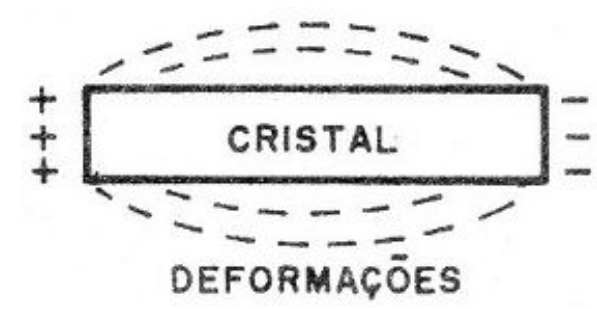

(a)

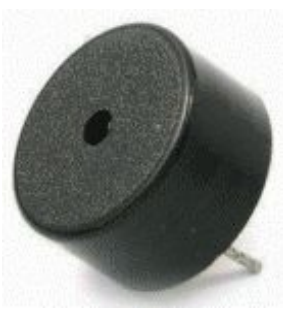

(b)

Figura 7. (a) Diferença de potencial elétrico em materiais piezoelétricos. (b) Buzzer. Fonte: (BRAGA, 2017).

\subsubsection{Diodo Emissor de Luz}

O diodo emissor de luz (LED) é um dispositivo semicondutor capaz de converter energia elétrica em energia luminosa. Assim como os diodos tradicionais, permitem a passagem da corrente elétrica apenas em um sentido. Na Figura 8 é possível visualizar LEDs de alto brilho.

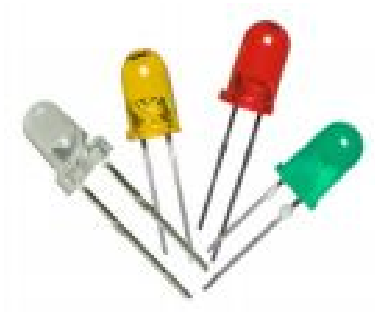

Figura 8. LEDs de alto brilho.

Fonte: (PINTO, 2008).

Em sistemas de alarme, os LEDs são utilizados para fins de iluminação indicativa e para sinalizar em casos de irregularidades. O que reforça a utilização deste componente em sistemas embarcados é a operação em corrente contínua e a baixa tensão de condução, entre 2,5 e $4 \mathrm{~V}$. O 

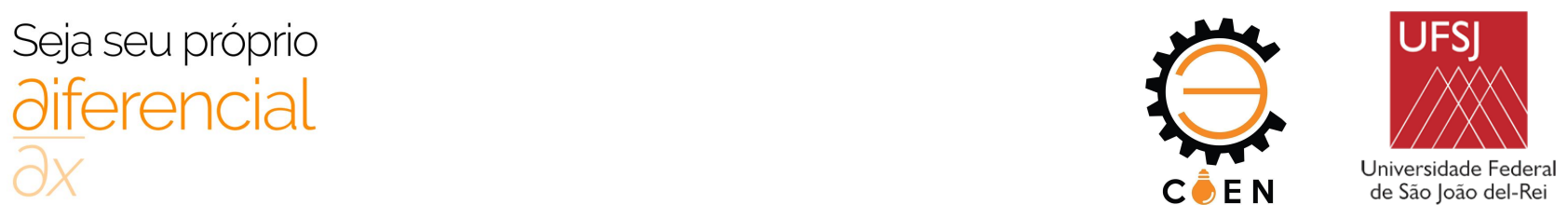

controle da intensidade luminosa do LED é realizada por meio da sua corrente de polarização, o que torna esta relação proporcional. Quanto maior o valor da corrente, maior será a intensidade da luz (PINTO, 2008).

\section{MATERIAIS E MÉTODOS}

Para alcançar o objetivo proposto neste trabalho, fez-se a escolha de dois sensores para o sistema, um de presença e um de contato, sendo o de presença um sensor PIR, que tem por finalidade detectar o movimento no interior do laboratório em local estratégico, e o de contato é o sensor magnético, que será posicionado em locais de acesso, como por exemplo, janelas.

Ambos os sensores podem se comunicar diretamente com o Arduino, o qual processa o sinal analógico/digital, no caso do sensor PIR, e um pulso, no caso do sensor magnético, sendo ambos identificados por meio do código inserido no microcontrolador. Em seguida, o Arduino executa o comando nos atuadores, os quais são um LED e um buzzer, constituindo em um sinal luminoso e um sonoro. Existem ainda os dispositivos para entrada e visualização de dados, que são o teclado multiplexado matricial 4x4 e um display de cristal líquido (LCD) 16x2.

Inicialmente, o sistema começa desativado, e então aparece no display a inicialização com a opção de entrada para as senhas cadastradas. Ao inserir a senha, o código compara cada caractere e verifica se a senha está correta, indicando de forma textual. Caso a senha esteja correta aparecerá a escrita no display "Senha correta! Alarme ativado." e em seguida o LED ficará aceso indicando que o sistema está ativado. Caso contrário, será mostrado no display a indicação "Senha incorreta!" e após alguns segundos voltará para a tela inicial para uma nova tentativa. Após o alarme ser ativado os sensores são acionados e caso detectem algum evento fornecem o sinal para o disparo do alarme. Se necessário, o usuário cadastrado pode desativar o alarme após ser ativado, ou caso ele dispare, utilizando a mesma senha para ativação.

O fluxograma da Figura 9 ilustra a lógica de atuação do sistema com as entradas, saídas e microcontrolador.

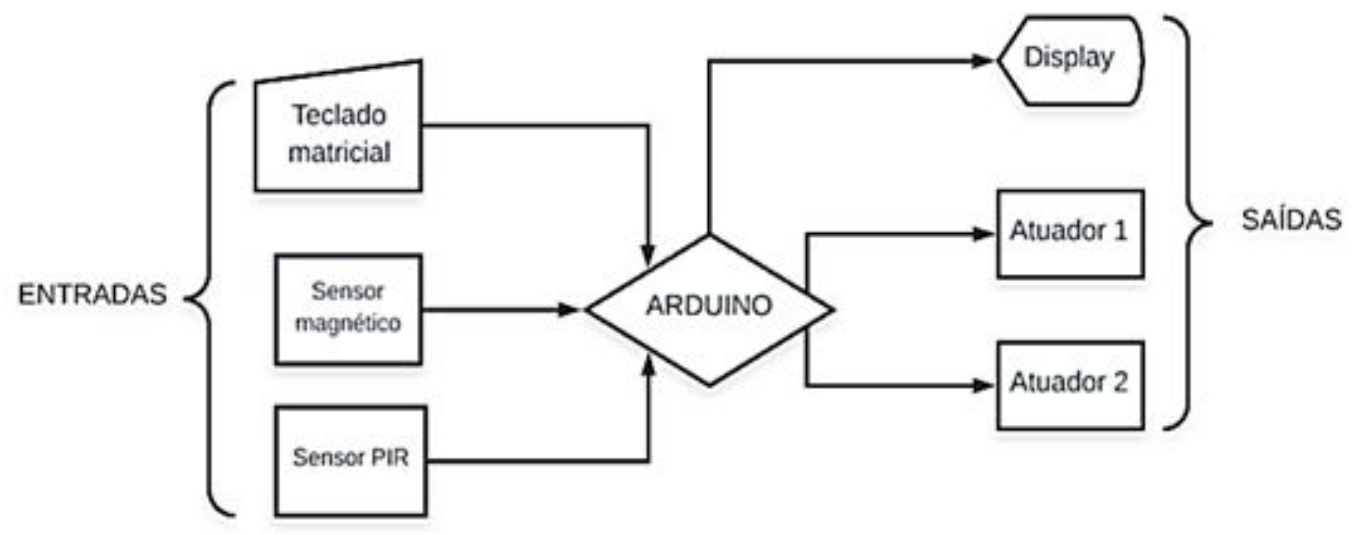

Figura 9. Fluxograma representativo do sistema.

Fonte: Elaborado pelos autores. 

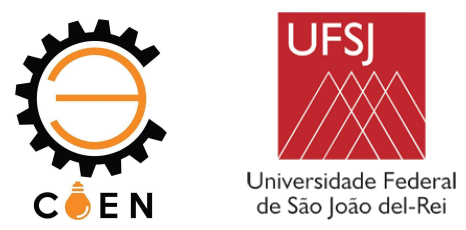

Para a validação desse sistema foi realizada uma simulação computacional por meio de uma plataforma online e gratuita da Autodesk, nomeada de "Tinkercad", na qual é possível inserir o programa desenvolvido e simular os sensores juntamente com o microcontrolador Arduino.

Logo em seguida realizaram-se os testes em bancada eletrônica, na qual foi testado individualmente cada componente para aferir o seu funcionamento correto e posteriormente testado o sistema completo, executando os mesmos testes efetuados na simulação.

\section{RESULTADOS}

\subsection{Simulação computacional}

O Tinkercad fornece os componentes necessários para a simulação, possui interface amigável, proporcionando a aferição do comportamento do sistema. O circuito montado na simulação e o seu funcionamento podem ser visualizados na Figura 10.

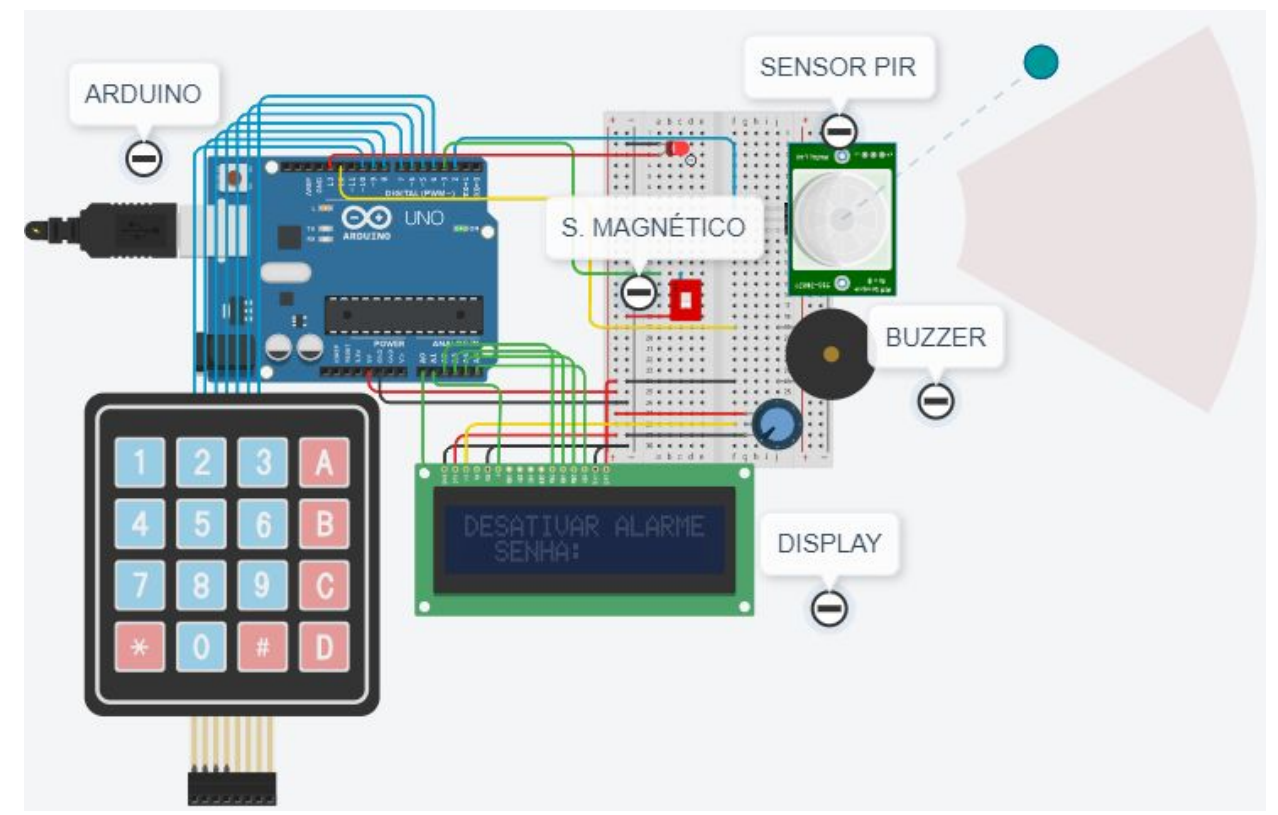

Figura 10. Simulação do circuito proposto na plataforma online Tinkercad.

Fonte: Elaborado pelos autores.

\subsection{Testes em bancada eletrônica}

Após validar o sistema de alarme na simulação computacional, a próxima etapa consistiu em efetuar os testes em bancada eletrônica. Iniciou-se então os testes dos componentes de forma individual para aferir o seu funcionamento, e logo em seguida o sistema completo. Os testes em bancada podem ser visualizadas na Figura 11 e 12. 
Seja seu próprio

aiferencial

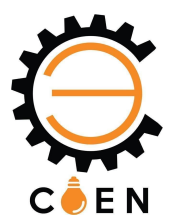

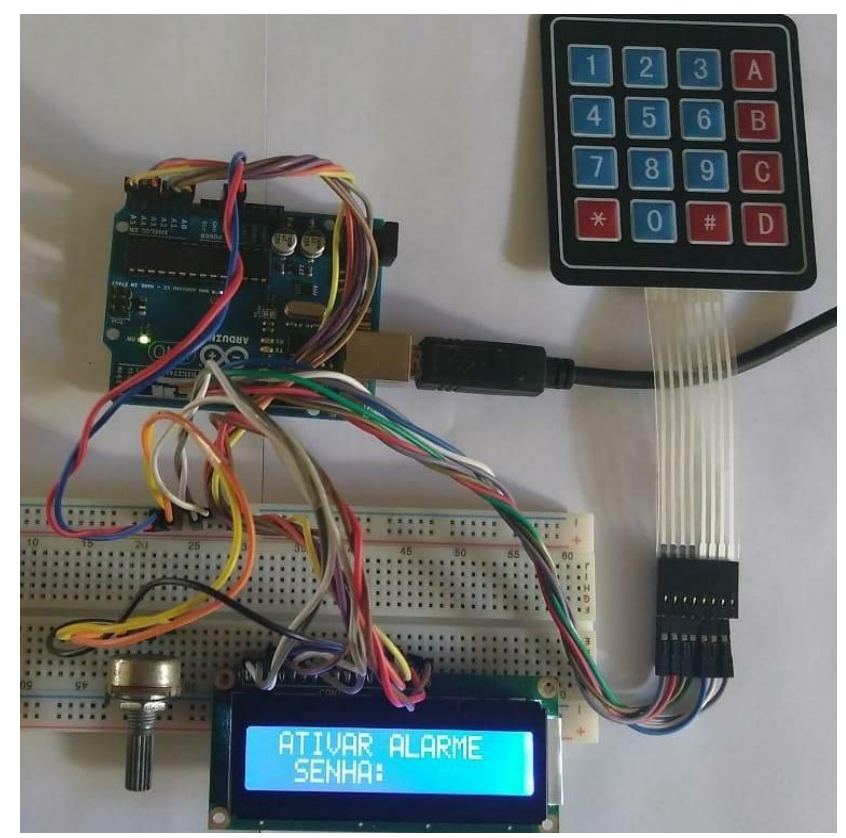

(a)

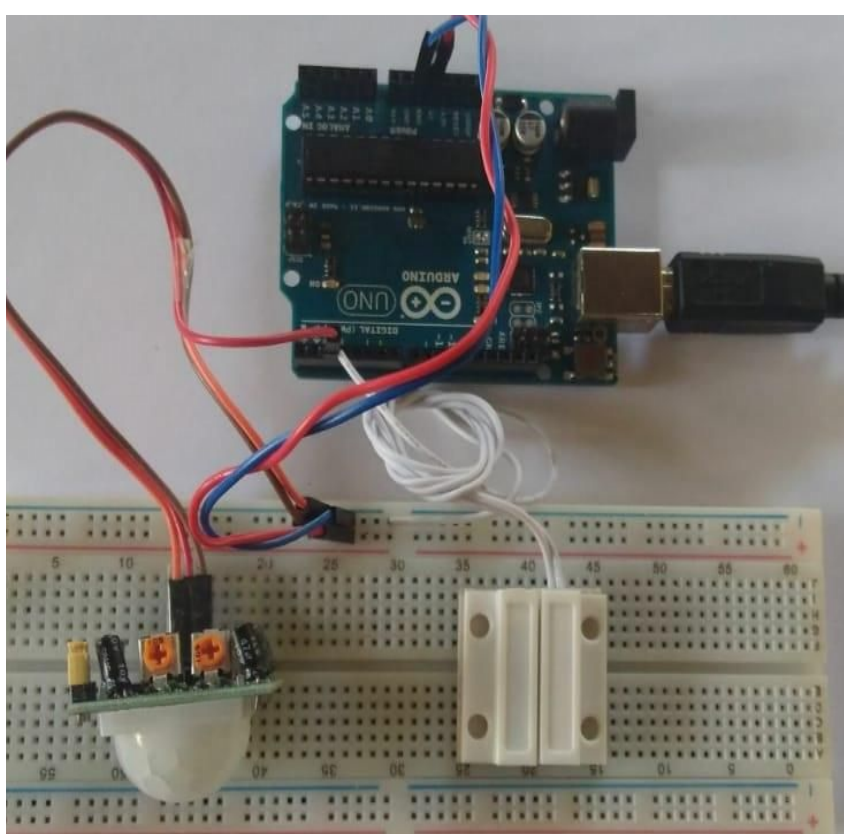

(b)

Figura 11. Testes realizados em bancada (a) testes no teclado e display (b) testes nos sensores. Fonte: Elaborado pelos autores.

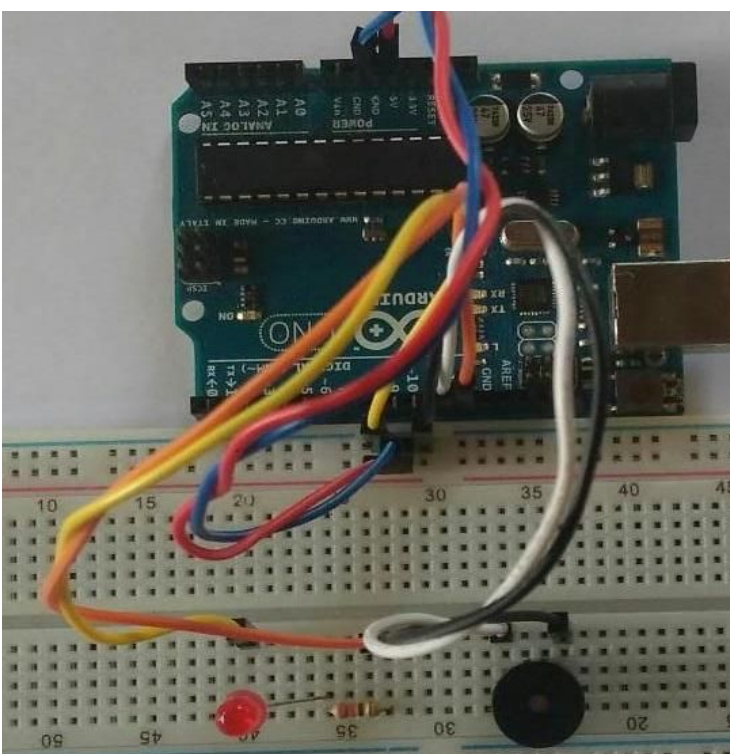

(a)

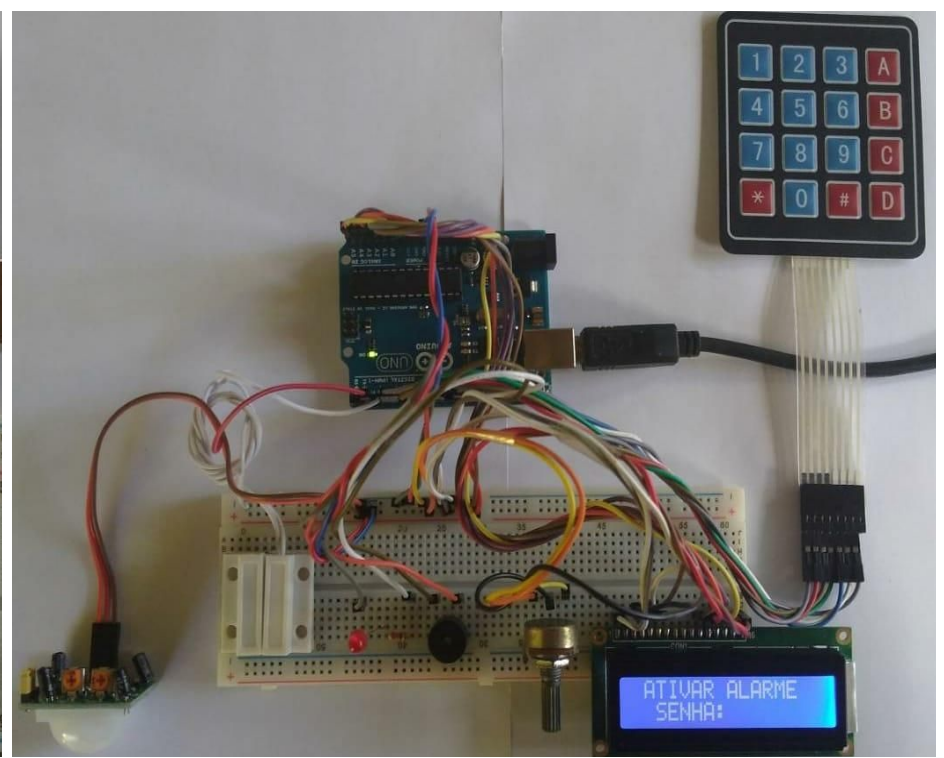

(b)

Figura 12. Testes realizados em bancada (a) testes com os atuadores (b) teste com o sistema completo.

Fonte: Elaborado pelos autores. 

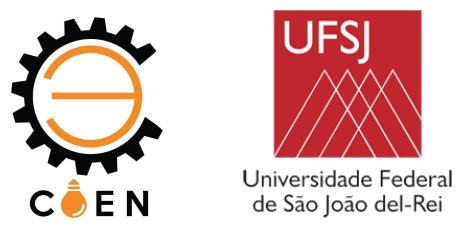

A validação do protótipo em bancada possibilitou a realização de uma comparação entre os custos dos sistema proposto pelo trabalho e os já existentes no mercado. Os valores dos equipamentos para desenvolvimento do protótipo foram obtidos no site Baú da Eletrônica e se encontram na Tabela 1 (BAÚ DA ELETRÔNICA, 2019).

Tabela 1. Custos referentes aos equipamentos do protótipo.

\begin{tabular}{|l|c|}
\hline \multicolumn{1}{|c|}{ Componente } & Valor (R\$) \\
\hline Arduino Uno & 49,41 \\
\hline Sensor de presença PIR & 9,81 \\
\hline Sensor magnético & 17,99 \\
\hline Teclado matricial 4x4 & 10,71 \\
\hline Display LCD 16x2 & 15,21 \\
\hline LED de alto brilho & 0,23 \\
\hline Resistor & 0,07 \\
\hline Buzzer & 1,35 \\
\hline \multicolumn{1}{|c|}{ TOTAL } & $\mathbf{1 0 4 , 7 8}$ \\
\hline
\end{tabular}

Fonte: Elaborado pelos autores.

Os sistemas de alarme existentes no mercado atual e que possuem características de funcionamento semelhantes ao protótipo desenvolvido estão sendo comercializados em uma plataforma digital por valores em média de $\mathrm{R} \$ 160,00$. Tomando como base tais valores, a viabilidade financeira do protótipo desenvolvido é constatada, uma vez que o preço para desenvolvimento do sistema proposto é de RS 104,78.

\section{CONCLUSÕES}

Diante da crescente demanda por segurança, seja em ambientes residenciais ou educacionais, a aplicação de tecnologias de automação fornece inovação no que diz respeito à proteção de bens patrimoniais. O custo acessível dos componentes eletrônicos, tal como o sensor PIR e o sensor magnético, tornam o sistema desenvolvido viável, quando comparado com os produtos comercializados no mercado.

Por meio dos resultados obtidos é possível afirmar que o sistema proposto foi validado e atendeu ao objetivo estabelecido neste trabalho. Com enfoque em ambiente laboratorial do IFMG Campus Formiga o presente trabalho demonstra que tais laboratórios poderiam ser monitorados por 

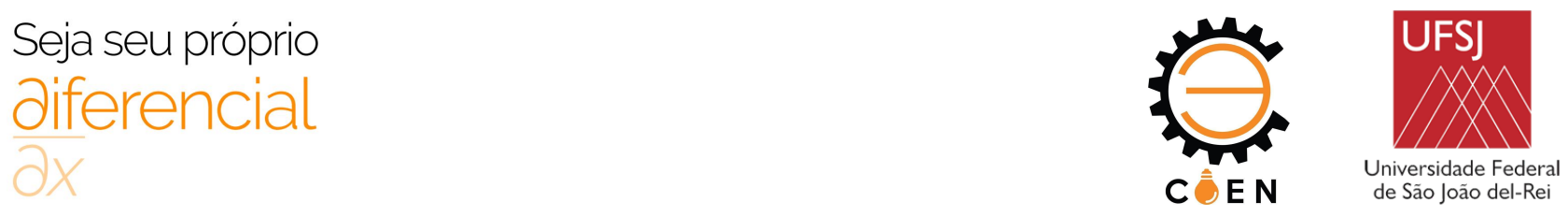

um sistema automatizado e a demanda por segurança armada poderia ser limitada, tendo redução de custos com empresas terceirizadas.

Em trabalhos futuros, o protótipo desenvolvido poderia ser transformado em produto, para isso, é necessário realizar algumas melhorias, tais como: a inserção de uma trava eletrônica na entrada do laboratório no sistema acionado por relé, estando esta associada ao alarme; substituição dos atuadores utilizados por atuadores de potência que fornecem uma operação em escala real e possível comunicação do sistema com algum servidor ou smartphone.

\section{AGRADECIMENTOS}

A todos os integrantes do Grupo de Pesquisa CNPq, GSE (Grupo de Soluções em Engenharia), pela interação e colaboração no desenvolvimento do presente trabalho, assim como ao IFMG - Campus Formiga.

\section{DIREITOS AUTORAIS}

Os autores são os únicos responsáveis pelo conteúdo das informações contidas neste artigo.

\section{REFERÊNCIAS}

ARDUINO. Getting Started with Arduino and Genuino UNO. 2017. Disponível em: $<$ https://www.arduino.cc/en/Guide/ArduinoUno>. Acesso em: 11 jul. 2019.

Baú da Eletrônica. 2019. Disponível em: <http://www.baudaeletronica.com.br/>. Acesso em: 13 jul. 2019.

BRAGA, N. C. Como funcionam as cápsulas ou buzzer cerâmicos. Instituto Newton C. Braga. 2017.

Disponível

em:

$<$ https://www.newtoncbraga.com.br/index.php/como-funciona/15090-como-funcionam-as-capsulas -ou-buzzer-ceramicos-art1702>. Acesso em 12 jul. 2019.

BRAGA, N. C. Sensores magnéticos de alarme. Instituto Newton C. Braga. 2014. Disponível em: $<$ http://www.newtoncbraga.com.br/index.php/como-funciona/1796-art265/>. Acesso em 12 jul. 2019.

BUCKMAN, G. Desenvolvimento de um protótipo de baixo custo para segurança residencial. Monografia de Graduação em Engenharia de Controle e Automação - Universidade Federal de Ouro Preto, 47 p., 2016.

HABICAMP. Cresce a busca por segurança residencial no Brasil. 2018. Disponível em: $<$ https:/habicamp.com.br/cresce-a-busca-por-seguranca-residencial-no-brasil/ $>$. Acesso em: 11 jul. 2019. 

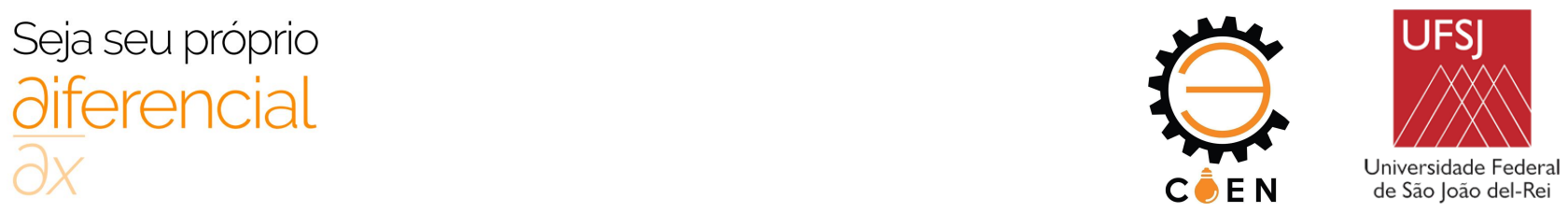

LIMA, I. Sensor magnético com fios para portas e janelas. Autocore Robótica. 2019. Disponível em: $\quad<$ https://www.autocorerobotica.com.br/sensor-magnetico-com-fio-para-portas-e-janelas $>$. Acesso em: 11 jul. 2019.

MADEIRA, Daniel. Sensor de presença com Arduino | PIR HC-SR501. 2017. Disponível em: $<$ https://portal.vidadesilicio.com.br/sensor-de-presenca-hc-sr501/>. Acesso em: 11 jul. 2019.

MARCHESAN, M. Sistema de monitoramento residencial utilizando a plataforma Arduino. Santa Maria, Brasil, 62 p., 2012.

MOTA, A. D. Ampolas de reed switch NA - Sensor magnético. Vida de Silício. 2019. Disponível em: <https://www.vidadesilicio.com.br/reed-switch-sensor-magnetico>. Acesso em: 11 jul. 2019.

NEVES, R. V. Controle de dispositivos em domótica via smartphone. Viçosa, Brasil, 38 p., 2015.

PINTO, R. A. Projeto e implementação de lâmpadas para iluminação de interiores empregando diodos emissores de luz (LED). Dissertação de Mestrado em Engenharia Elétrica - Universidade Federal de Santa Maria, 138 p., 2008.

SOUZA, F. Arduino Uno. Portal Embarcados. 2013. Disponível em: $<$ https://www.embarcados.com.br/arduino-uno/>. Acesso em: 12 jul. 2019.

\section{DEVELOPMENT OF PROTOTYPE ALARM SYSTEM FOR LABORATORY ENVIRONMENT}

ABSTRACT: Laboratory environments have equipment of high financial value, a fact that increases the probability of possible thefts in these places. In most cases armed security is employed, so that such occurrences do not occur. In this context, the use of control and residential automation technologies becomes an alternative, specifically sensory alarm systems, whose purpose is to delimit and control the flow of people in defined environments, in order to reduce the possibility of theft. Therefore, this work presents the development of a small scale model of an alarm for a laboratory environment. This device uses the embedded Arduino platform and includes presence and contact sensing, audible and luminous alarm system and access control carried out by predefined password, which is inserted by a keyboard and viewed on a screen. The prototype has the function of monitoring the environment in an automated way, so that once locked by those in charge will have their restricted access.

KEYWORDS: Alarm system, control and automation technologies, Arduino. 